\title{
IMPACTO DE SALVAGUARDAS EN EL COMERCIO EXTERIOR: CASO DE ESTUDIO MÉXICO-ECUADOR EN UNA EMPRESA DE ELECTRODOMÉSTICOS
}

\author{
Impact of safeguards on foreign trade. Study case: Mexico-Ecuador appliance- \\ manufacturing Company \\ Paula María Servín-Flores \\ MSc. en Negocios Internacionales. Universidad Autónoma de Querétaro, Querétaro-México, \\ paulamaria7@yahoo.com \\ Ilia Violeta Cázares-Garrido \\ PhD en Administración. Universidad Autónoma de Querétaro, Querétaro-México, \\ violetacg@yahoo.com
}

\begin{abstract}
Cómo citar / How to cite
Servín-Flores, P. M. y Cázares-Garrido, I. V. (2017). Impacto de salvaguardas en el comercio exterior caso de estudio México-Ecuador en una empresa de electrodomésticos. Revista CEA, 3(5), 41-57.
\end{abstract}

Recibido: 10 de marzo de 2016

Aceptado: 14 de septiembre de 2016

\section{Resumen}

El comercio exterior de México se ubica entre los primeros jugadores en el comercio internacional; en 2013 obtuvo el décimo lugar como exportador y noveno como importador a nivel mundial, y el primero en ambas categorías entre los países de América Latina y el Caribe. Los aranceles, tal como las salvaguardas protegen sectores concretos, restringen temporalmente las importaciones de mercancías idénticas, similares o directamente competidoras a las de producción nacional para prevenir o remediar un daño y facilitar el ajuste de productores nacionales. El objetivo de la investigación es conocer el impacto de la salvaguarda en México impuesta por el gobierno ecuatoriano, desde la perspectiva de una empresa exportadora en México, posiciones en el mercado, dicha sobretasa fue aplicada a la importación de productos electrodomésticos en marzo del 2015. Los resultados muestran los efectos de dicha medida proteccionista y las implicaciones negativas para los exportadores mexicanos, a través del análisis financiero comparativo de antes y después de la aplicación de dicha medida, mostrando el comportamiento en ventas, costo de aranceles y la relación entre ellos.

Palabras clave: Ecuador, comercio internacional, México y salvaguardas.

\begin{abstract}
Mexico's foreign trade is among the first worldwide. In 2013, it was the tenth exporter and ninth importer around the globe, and it took the first position in both categories among Latin American and Caribbean countries. Tariffs such as safeguards protect specific sectors and temporarily restrict imports of identical, similar or directly competitive to domestic goods to
\end{abstract}


prevent or repair some damage and enable the adaptation of domestic manufacturers. The objective of this research is to establish the impact of the safeguards imposed by the Ecuadorian government from the perspective of a Mexican export company and its positions in the market. Said surtax was applied to the importation of electrical appliances in March 2015. The results show the effects of this protectionist measure and the negative implications for Mexican exporters by analyzing the financial situation before and after its enforcement. Sales behavior, cost of tariffs and the relationship between them are described.

Keywords: Ecuador, international trade, Mexico, safeguards.

\section{INTRODUCCIÓN}

México se ha enfocado en el fomento a la exportación como uno de los pilares más importantes de su economía. El país tiene una economía comercial favorable, ya que ha logrado adaptarse a la economía mundial. Para lo anterior, ha sido necesario llevar a cabo relaciones estrechas y estratégicas entre el Gobierno, los diversos organismos y las empresas, buscando una sinergia positiva que fomente la producción nacional, el comercio internacional, así como las inversiones extranjeras.

A partir de que México se unió al Acuerdo General sobre Aranceles Aduaneros y Comercio (GATT) en 1986, ha firmado una serie de tratados comerciales bilaterales $y$ regionales; el país cuenta con una red de 11 Tratados de Libre Comercio con 46 países (TLC), 32 Acuerdos para la Promoción y Protección Recíproca de las Inversiones (APPRI) con 33 países y 9 Acuerdos de Alcance Limitado (Acuerdos de Complementación Económica y Acuerdos de Alcance Parcial) entre los que se encuentra el Acuerdo de Alcance Parcial (APP.
$\left.\mathrm{R} \mathrm{N}^{\circ} 29\right)$ que rige las relaciones comerciales de México con Ecuador desde 1987.

Además, México participa activamente en organismos y foros multilaterales y regionales como la Organización Mundial del Comercio (OMC), el Mecanismo de Cooperación Económica Asia-Pacífico (APEC), la Organización para la Cooperación y Desarrollo Económicos (OCDE) y la Asociación Latinoamericana de Integración (ALADI).

La industria de electrodomésticos ha resultado ser para el país uno se los sectores con mayor actividad en el comercio internacional. México es el principal exportador de electrodomésticos en América Latina y el quinto a nivel mundial.

En medio de las circunstancias internacionales que se presentaron durante el 2015, como la apreciación del dólar en los mercados internacionales y la caída del precio del petróleo, Ecuador se vio afectado con pérdida de competitividad y disminución de ingresos por exportaciones, por lo que adoptó como medida temporal para contrarrestar este efecto, la imposición de salvaguardas por balanza comercial a la importación de 2800 partidas entre los que se encuentran los productos electrodomésticos. La presente investigación revela la repercusión comercial de dicha medida, que entró en vigor en marzo del año en mención, el estudio fue realizado una de las empresas de electrodomésticos en México líder en línea blanca en el continente americano.

Mediante un análisis financiero de los 5 años previos a la aplicación de la medida arancelaria, se exhibe el fenómeno desde la perspectiva de una empresa exportadora en México a través del análisis de informes financieros, reportes de ventas y cálculo de costos de impuestos pagados. 


\section{MARCO TEÓRICO}

La actividad comercial ha cambiado a lo largo de los siglos, adaptándose en los últimos 10 años para cubrir las necesidades y obtener una satisfacción, tanto para compradores como para vendedores. De esta forma, Witker y Hernández (2008) afirman que la evolución que ha tenido el comercio a través de la historia presenta cuestiones de gran importancia para entender la configuración actual del comercio.

Los términos «comercio internacional» $y$ "comercio exterior» son confundidos y en muchas ocasiones se utilizan de manera indistinta, es por ello importante aclarar la diferencia. Por una parte, el comercio exterior es un factor clave en la actividad económica de cualquier país, de acuerdo con Witker y Hernández (2008), el término hace referencia al intercambio comercial de un país con relación a los demás, por ejemplo, tomando como referencia a México, diríamos que el comercio exterior de México es aquel que realiza con las diferentes naciones con las cuales comercia.

Por otra parte, el término comercio internacional es un concepto más amplio, pues abarca el flujo de relaciones comerciales internacionales, sin hacer referencia a un país en específico. Los autores Samuelson y Nortdhaus (2005) y Francisco Mochón (2008), definen al comercio internacional como el intercambio (importación y exportación) de bienes, servicios y capital financiero entre los diferentes países. De manera más detallada, se define como «el conjunto de movimientos comerciales y financieros, y en general todas aquellas operaciones, cualquiera que sea su naturaleza, que se realicen entre naciones; es pues un fenómeno universal en el que participan las diversas comunidades humanas» (Osorio, 1995, p. 48). El intercambio según Ballesteros (1998), se realiza utilizando divisas y está sujeto a regulaciones adicionales que establecen los participantes en el intercambio y los gobiernos de sus países de origen.

De acuerdo con el Instituto Nacional de Comercio Exterior y Aduanas (INCEA), en México, la diferencia entre los términos está en que el comercio internacional incorpora las transacciones globales de los productos, mientras que en el comercio exterior es un país en específico o un bloque comercial el que establece relaciones de intercambio comercial con el resto del mundo. De manera puntual, Vera (2015) contrasta los términos y manifiesta que el comercio exterior tiene un carácter nacional y está sujeto al derecho internacional privado, mientras que el comercio internacional tiene un carácter supranacional y se rige por el derecho internacional público.

De acuerdo con González et al. (2009), en un principio el comercio internacional surgió con objeto de obtener productos (bienes y servicios) por parte de los países que no eran capaces de producirlos por sí mismos. Actualmente, buscando la eficiencia en la asignación de los recursos, los países no solo importan aquello que no pueden producir, sino también los bienes y servicios que aun pudiéndose producir, pues resultan más costosos de elaborar en el interior que si son importados.

El comercio internacional se ha mantenido en constante trasformación a lo largo de la historia del hombre, determinada en mayor medida por la innovación tecnológica, evolucionando aún más a partir del siglo XX producto de las dos guerras mundiales y la gran depresión de los años 30; en 1946, una vez finalizada la Segunda Guerra Mundial, y con el objetivo de lograr una recuperación de la economía mundial, surgen instituciones de carácter multilateral, tales como: el Banco Mundial, Fondo Monetario Internacional (FMI) y el Acuerdo General sobre Aranceles y Comercio (GATT), este último con la finalidad de impulsar 
rápidamente la liberalización y el crecimiento del comercio internacional.

EI GATT realizó siete rondas de negociaciones multilaterales. La ronda final, culminó con la suscripción de un conjunto de compromisos por parte de los países miembros, entre los cuales se comprendió el acuerdo para establecer la Organización Mundial de Comercio (OMC), base jurídica e institucional del sistema multilateral de comercio.

Con el crecimiento del Comercio Internacional también surge la necesidad de regularlo a través de acuerdos y políticas comerciales. Los aranceles son la forma más antigua y simple de política comercial. Inicialmente, tenían como finalidad ser una fuente de ingresos para el Estado y con el tiempo se fueron convirtiendo en un instrumento de Política Económica para preservar el empleo y equilibrio del sector exterior (González et al., 2014), así como para proteger sectores nacionales concretos, conteniendo las importaciones y desviando la demanda interna de los productos extranjeros a los nacionales para beneficio de los productores locales.

Un arancel es un impuesto aplicado a la importación, cuyo efecto es aumentar el coste de llevar bienes a un país (Krugman et al, 2012). Por su parte, Bengochea et al. (2002) mencionan que el gravamen puede ser también aplicado a las exportaciones, aunque se presenta con muy poca frecuencia.

De acuerdo con la definición de la Organización Mundial del Comercio (OMC), se denominan aranceles a los derechos de aduana aplicados a las importaciones de mercancías. Los aranceles proporcionan a las mercancías producidas en el país una ventaja en materia de precios con respecto a las mercancías similares importadas, y constituyen una fuente de ingresos para los gobiernos. Los aranceles tienen dos propósitos: (1) Proteger los bienes nacionales; (2) Servir como fuente de ingreso para el Estado.

Los derechos arancelarios, como se muestran en la Fig. 1, se pueden clasificar atendiendo a tres criterios: forma en que se grava, cuantía del arancel y procedencia de mercancías; en donde se consideran los principios del funcionamiento de la OMC-GATT, por el cual todos los países de comprometen a tratar de igual manera a sus socios comerciales.

Krugman et al. (2012) afirman que la importancia de los aranceles ha disminuido en los tiempos modernos, porque hoy en día los Estados prefieren proteger las industrias nacionales, mediante una variedad de barreras no arancelarias, tales como cuotas de importación y restricciones a la exportación que limitan en cantidades.

Algunos autores como O'Sullivan y Sheffrin (2003) exponen argumentos a favor de las medidas proteccionistas y hablan de tres posibles motivos para adoptar medidas que restrinjan el comercio: a) Proteger a los trabajadores de las industrias (aunque el resultado puede ser una producción menos eficiente, precios más altos y disminución del consumo); b) ayudar a las industrias nacientes hasta que maduren y sean capaces de competir y, c) ayudar a las empresas nacionales a crear monopolios en los mercados mundiales. 

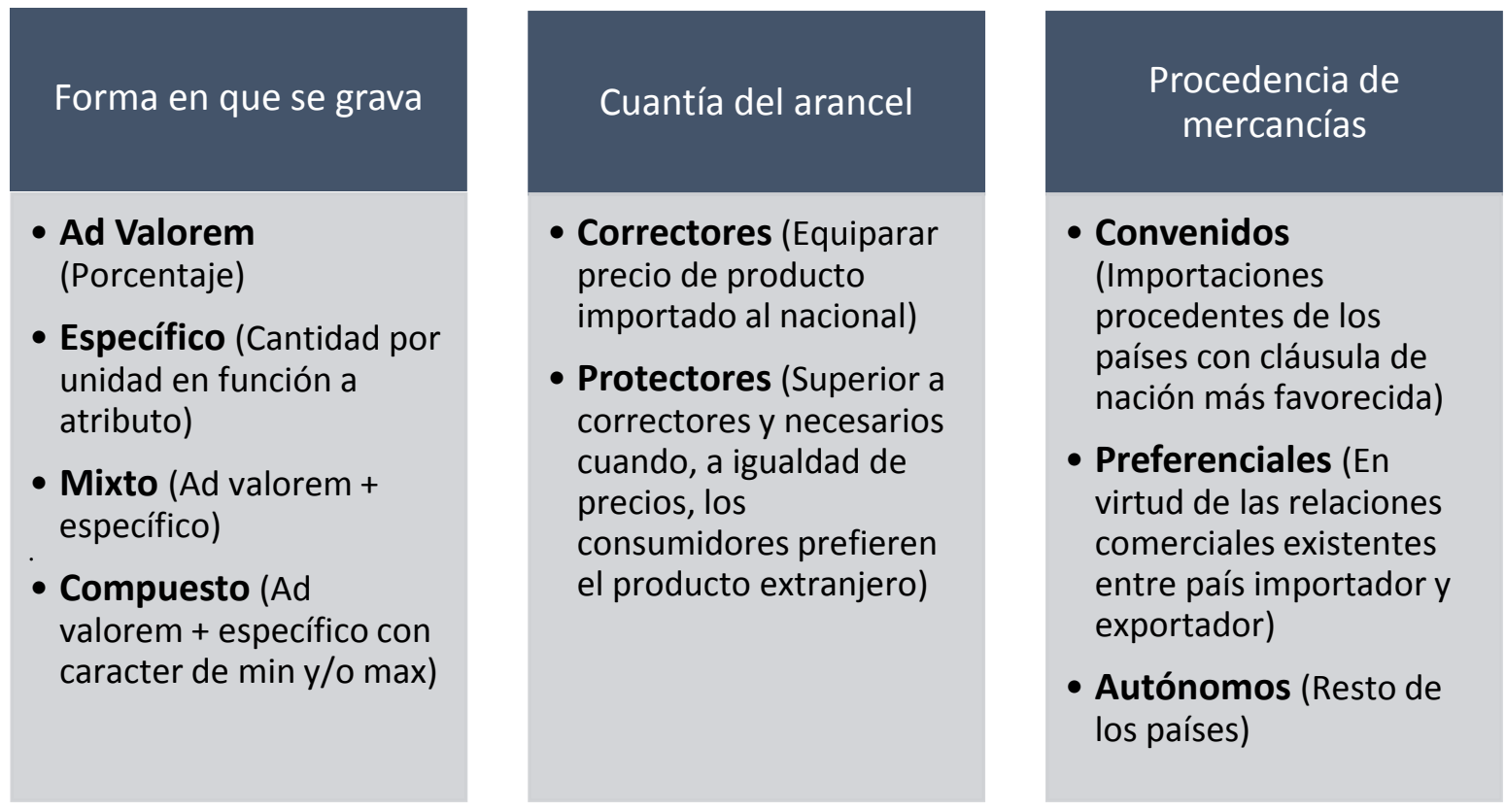

Figura 1. Clasificación de los derechos arancelarios

Figure 1. Classification of customs tariff

Fuente: elaboración propia basada en González et al., 2014.

Los mismos autores mencionan que la imposición de aranceles también puede tener efectos negativos, ya que hay muchos costes indirectos derivados de su imposición tienden a limitar aún más el comercio, pueden provocar represalias de los socios comerciales con sus propios aranceles (perjudicando a los productores exportadores del país que impuso inicialmente un arancel), fomentan el contrabando, pues crean una diferencia entre el costo de compra de los bienes restringidos en el extranjero y dentro de la economía protegida. Otro problema es que al quitar la presión para incrementar la productividad conducen a ineficiencias en la industria protegida, además de dificultar el retiro de la protección.
Para González et al. (2014), el establecimiento aranceles tiene principalmente 4 efectos sobre las importaciones, los cuales se muestran en la Fig. 2.

El sector de electrodomésticos incluye cualquier aparato, utensilio o máquina, usado en el hogar, que utilice electricidad como fuente de energía. Esta industria se divide en dos grupos: los enseres mayores y menores, clasificados de acuerdo con la facilidad para desplazarlos.

La industria de aparatos electrodomésticos generó ingresos por 237,000 millones de dólares en 2010 y creció a una tasa promedio anual de $4.6 \%$ en el periodo 2005-2009. Los principales países exportadores de electrodomésticos son China, Alemania e Italia. 


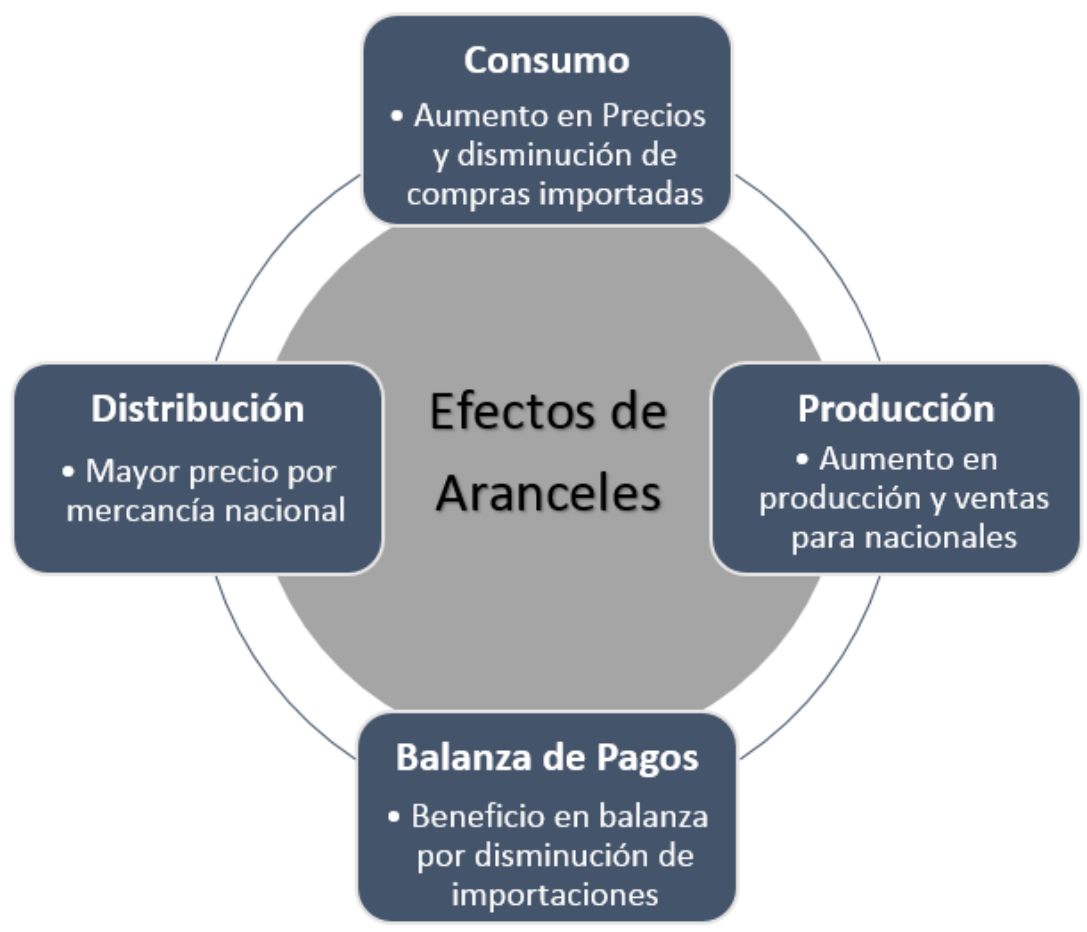

Figura 2. Efecto de aranceles sobre importaciones Figure 2. Effect of tariffs on imports

Fuente: elaboración propia basada en González et al., 2014.

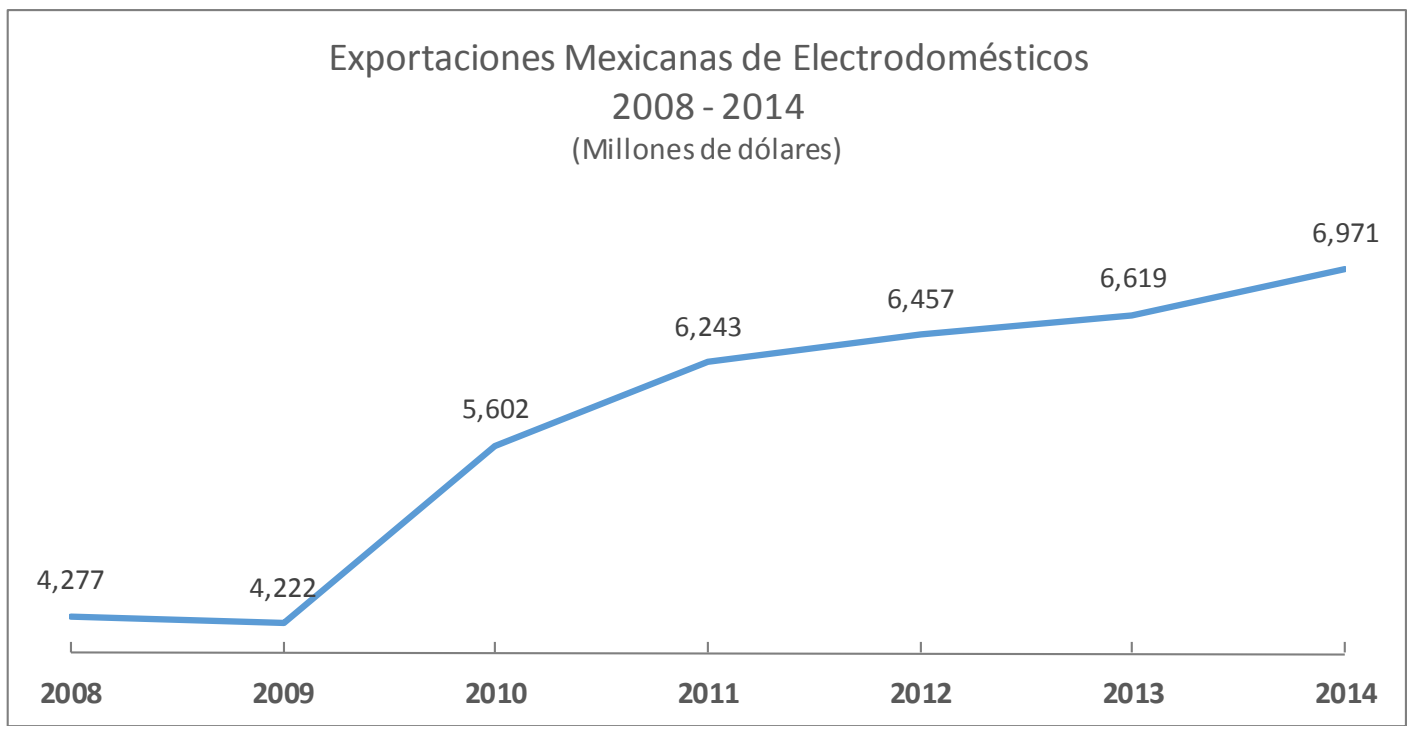

Figura 3. Exportaciones Mexicanas de Electrodomésticos

Figure 3. Mexican Exports of Domestic Appliances

Fuente: elaboración propia basada en los datos de ProMéxico (Perfil del sector consultado 10 de marzo 2016). 
México se colocó como el quinto exportador de electrodomésticos del mundo en el 2014 y se mantuvo como el séptimo productor mundial. Como lo muestra la Fig. 3, el país exportó en ese año 6,971 millones de dólares. A nivel global, México es líder en las exportaciones de refrigeradores y congeladores de dos puertas; tiene la segunda posición en ciertos acondicionadores de aire y está situado en el tercer lugar en las de lavadoras con capacidad superior a 10 kilos y en refrigeradores de comprensión y estufas de gas.
De acuerdo con cifras reportadas en Global Trade Atlas, en 2014 el destino más importante de exportación del sector fue Estados Unidos (86\%), el resto se dirigió principalmente a Canadá y Colombia. En este mismo año, la producción de electrodomésticos del país fue de 7,199 millones de dólares y, según la consultoría Global Insight, sostendrá una tasa de crecimiento promedio anual de $4.2 \%$ hasta el 2020, para llegar a 9,215 millones de dólares como lo muestra la Fig. 4.

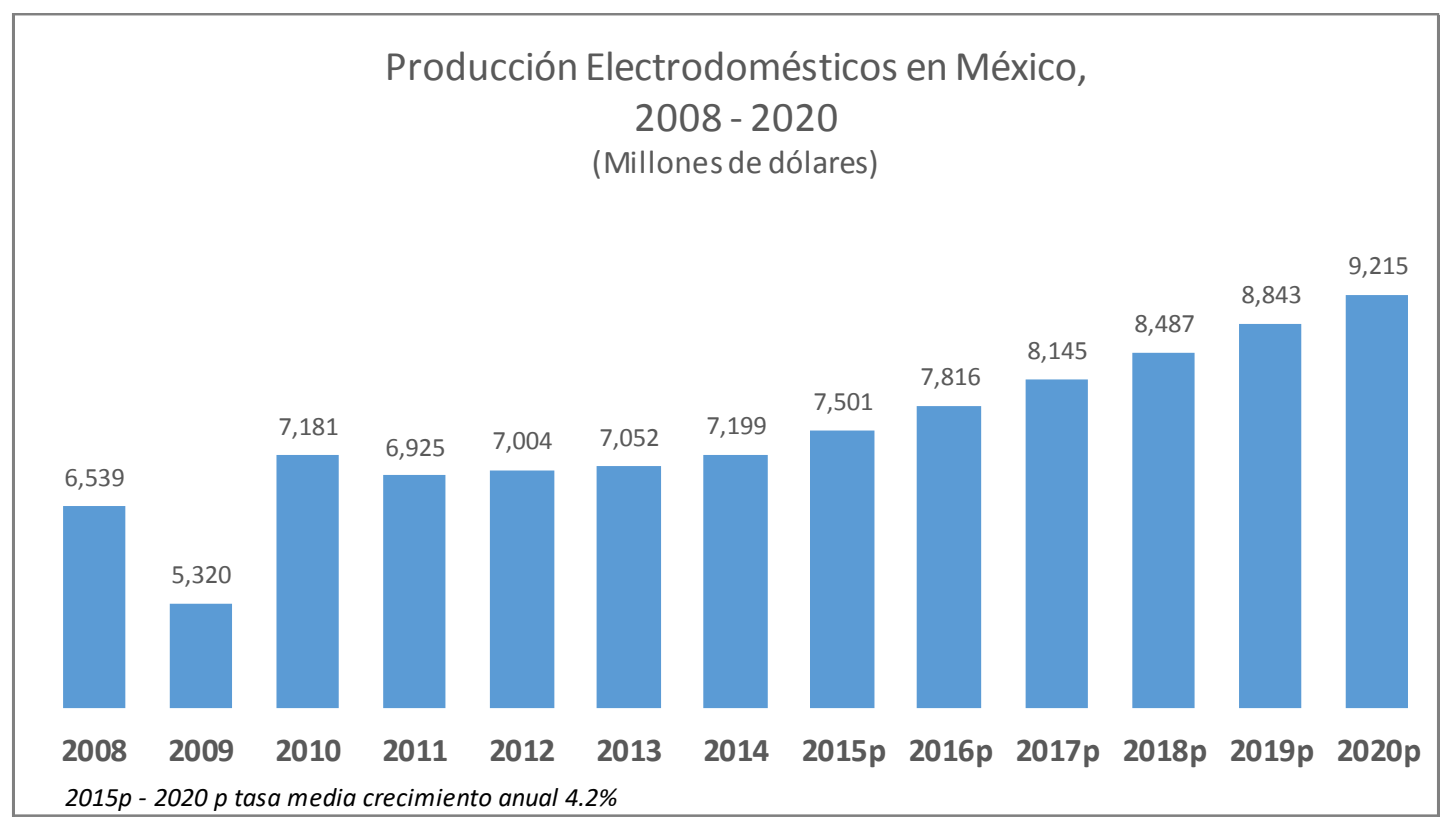

Figura 4. Producción de Electrodomésticos en México

Figure 4. Appliances Production in México

Fuente: Elaboración propia basada en datos de ProMéxico (Perfil del sector, consultado 10 de enero 2016).

De acuerdo con el Instituto Nacional de Estadística y Geografía de México (INEGI), en el país existen 261 unidades económicas relacionadas con la industria, las cuales emplean alrededor de 63,936 personas. Los estados con mayor producción son Nuevo León, Guanajuato, San Luis Potosí y Querétaro. Las principales compañías transnacionales de electrodomésticos establecidas en México son:
Electrolux (Suecia), General Electric (Estados Unidos), Koblenz (México), LG (Corea del Sur), Mabe (México), Samsung (Corea) y Whirlpool (Estados Unidos). Entre 2014 y 2015 , empresas como Faber North America, Kostal, Daewoo, Whirlpool, Procter \& Gamble y Electrolux, anunciaron inversiones que benefician y hacen crecer la industria de electrodomésticos del país. 
Algunos estudios revelan que los efectos negativos de las salvaguardas se pueden percibir en diversos puntos, Mendoza, (2006) indica que, en el caso de estudio de importaciones de triplay, esta medida mejoró la producción, lo efectos contrarios estuvieron presente en el bienestar del consumidor, hubo una reducción del consumo total del producto, otras industrias de la madera resintieron y percibieron una disminución del consumo.

En un caso de aplicación de salvaguardias arancelarios en el flujo de Ecuador-Colombia, Benavides Romo (2013) expone que durante el periodo 2009 a 2011 se realiza un análisis derivado de la crisis internacional al término del 2008. Ecuador aplica una medida de salvaguardas con la finalidad de frenar el volumen de importaciones e impedir que su balanza de pagos sufriera un déficit mayor. Uno de los hallazgos principales es la medida de salvaguarda que tuvo un efecto positivo a corto plazo, lo que ayudó a contrarrestar problemas de iliquidez interna, además de impulsar otros sectores de la economía, tal es el caso de la industria del calzado. La salvaguarda logró el objetivo de sosegar el consumo de bienes suntuarios, obviamente favoreciendo los productos nacionales. Sin embargo, el autor manifiesta que los consumidores en general sufrieron afectación en el aumento de precios en varios productos de consumo común de la sociedad, por lo que vivieron una disminución de su poder adquisitivo.

El caso del sector automotriz, las salvaguardas impuestas en Ecuador tuvieron efectos negativos que impactaron significativamente a la industria, de acuerdo con Muñoz (2017). La autora menciona que, si bien la aplicación de salvaguardas tiene como finalidad proteger la industria interna del país, dicha restricción ha generado un incremento en los precios de autos de una marca específica, y por lo tanto el porcentaje de ventas del producto tiene una afectación directa y negativa. El impacto además de las finanzas de la empresa se vio reflejado en el recurso humano que se dedicaba en a la producción y comercialización de automóviles.

\section{METODOLOGÍA}

México y Ecuador tienen una gran relación comercial, de acuerdo con el Banco Central Ecuador, en la última década el comercio bilateral entre México y Ecuador se ha quintuplicado, alcanzando los 1032 millones de dólares en 2013, de los cuales 911 millones correspondieron a exportaciones. La Secretaría de Economía en México, señala a su vez que el país mantiene inversiones en Ecuador por 5400 millones de dólares, a través de empresas mexicanas, entre las principales y de mayor tamaño se encuentran: América Móvil, Arca Continental, Mabe, Bimbo y Sygma.

En marzo 2015, el gobierno de Ecuador anunció la imposición de salvaguardas por balanza de pagos a 2800 partidas con sobretasas de $5 \%$, $15 \%$, $25 \%$ y hasta $45 \%$. Alrededor de 120 partidas vinculadas con electrodomésticos formaron parte de la Resolución 11 que el Comité de Comercio Exterior (Comex) emitió durante 15 meses, a partir de la fecha mencionada. La salvaguardia es una tasa adicional al arancel que ya se pagaba anteriormente; con esta medida la importación de electrodomésticos alcanzó el $65 \%$ de tasa en productos como refrigeradores y secadoras de ropa, el $75 \%$ en lavadoras, licuadoras, planchas, microondas, hornos y aspiradoras.

Por ello, el objetivo de la investigación es conocer los efectos de la imposición de las salvaguardas para el comercio exterior en las empresas de electrodomésticos. El análisis realizado en base a la recopilación de documentos, registros y reportes significativos de los últimos 5 años y análisis histórico de 
informes financieros, reportes de ventas y cálculo de costos de impuestos pagados. Dichas fuentes permitieron entender el fenómeno central de estudio para mostrar el efecto de los aranceles en las exportaciones. En particular, se enfocó la revisión en la repercusión que tuvo la imposición de la medida de salvaguardas en los resultados comerciales de la empresa mostrándonos el comportamiento en ventas, costo de aranceles y la relación entre ellos.

De acuerdo con la definición del Banco de Comercio Exterior (Bancomext), las salvaguardas son medidas excepcionales de protección que utiliza un país para proteger temporalmente a determinadas industrias nacionales que se encuentran dañadas o que se enfrentan a una amenaza de daño grave, debido a un incremento significativo de las mercancías que influyen al mercado interno en condiciones de competencia leal, esto es, sin márgenes de dumping y sin recibir subsidio.

Este proyecto de investigación, busca evaluar el impacto de la imposición de la medida arancelaria de salvaguardas en las exportaciones de la empresa desde México hacia Ecuador. El tipo de estudio que se utilizó para la realización del documento fue una investigación descriptiva y analítica, histórico documental y explicativa.

La empresa objeto de nuestro estudio está dedicada a la manufactura de electrodomésticos en México, con más de 60 años de historia, éxito e innovación, se afianza en los años 80 como líder en línea blanca en el mercado mexicano y a partir de ahí se ha mantenido en constante crecimiento. En los años noventa, consolida su presencia en América Latina mediante alianzas estratégicas con países como Colombia, Venezuela, Perú y
Ecuador. Entre las fortalezas de la empresa está su estructura de manufactura y comercial que le han permitido ser pionero en productos de vanguardia con diseño, tecnología y calidad de clase mundial y mantenerse competitivos de acuerdo a los estándares y demandas del mercado actual. Sus líneas de producto principales son estufas, refrigeradores, lavadoras, secadoras, centros de lavado, campanas, entre otros productos que componen su portafolio. Actualmente la empresa tiene una presencia global, vendiendo sus productos en más de 70 países a lo largo del continente americano y resto del mundo.

El análisis se hizo en base a la recopilación de los datos históricos extraídos de documentos, registros y reportes significativos de los últimos 5 años (2010-2015), tales como informes financieros, reportes de ventas y cálculo de costos de impuestos pagados. Dichas fuentes permitieron entender el fenómeno central de estudio para mostrar el efecto de los aranceles en las exportaciones. En particular, el análisis se enfocó en la repercusión que tuvo la imposición de la medida de salvaguardas que impuso el gobierno de Ecuador a la importación de electrodomésticos en los resultados comerciales de la empresa principalmente en México.

La investigación se enfoca en un estudio de caso, la empresa, que por confidencialidad se omite el nombre, exporta a 11 países de Latinoamérica, principalmente. Para el propósito de evaluar el impacto de los aranceles en las relaciones comerciales, centramos el estudio en la región Andina, donde participa Ecuador; dicha empresa inició su actividad de exportación hacia Ecuador en 2009, quien impuso esta medida proteccionista en el 2015. 
Objetivos

Objetivo general

El documento tiene como objetivo analizar y evidenciar el impacto en el comercio y las exportaciones de una empresa en particular posicionada en el mercado, por el uso de las medidas arancelarias como estrategia proteccionista, como lo son las salvaguardas.

Objetivos específicos

- Conocer el origen de las medidas arancelarias y la historia del comercio internacional caso México-Ecuador

- Analizar el impacto de las salvaguardas en la empresa de estudio en sus operaciones de México y Ecuador

Pregunta central

¿De qué manera impactan las medidas arancelarias proteccionistas, como el uso de salvaguardas, los resultados de una empresa mexicanas de electrodomésticos con presencia en el mercado y con relaciones comerciales y de exportación hacia Ecuador?

Preguntas secundarias

- ¿Cuál es el origen de las medidas y su evolución en la historia del comercio internacional México-Ecuador?

- ¿Cuál es el impacto de las salvaguardas en la empresa de estudio en sus operaciones de México-Ecuador?

Las variables que se analizaron fueron:

Histórico de Ventas. Tendencia del comportamiento de las ventas en Ecuador de producto doméstico, así como de las ventas del producto exportado de México hacia dicho país, tanto en volumen de unidades como importe de venta en dólares (USD).
Costo de Aranceles. Análisis del comportamiento de la cuota por unidad de venta por concepto de aranceles derivados de la importación de electrodomésticos a Ecuador desde México.

A partir de estas variables analizadas, se pudo observar la relación que existe entre las ventas y el costo de aranceles y los efectos que estos pueden tener en los resultados de la empresa del estudio. Los comparativos que se realizaron fueron:

- Porcentaje de exportación de producto manufacturado en México (volumen de venta en unidades) hacia mercado Andina y Centroamérica.

- Comportamiento de exportación a Ecuador (Volumen de venta en unidades) de México.

- Ventas en Ecuador de producto manufacturado en Ecuador (venta en USD).

- Exportación de producto manufacturado en México hacia Ecuador (venta en USD).

- Ventas en Ecuador de producto doméstico en comparación con las ventas en el mismo periodo de producto importado de México.

- Costo unitario por concepto de aranceles de producto importado de México a Ecuador, tomando como base el primer año de los datos históricos analizados.

- Relación entre costo de arancel y nivel de exportaciones de México a Ecuador.

\section{RESULTADOS}

Dentro de este aparto se presentan la información financiera procesada, de tal manera que se pueda ver el comportamiento de las ventas antes y después de la implementación de la mediad arancelaria. Inicialmente, se observan las ventas de electrodomésticos en Ecuador de producto 
manufacturado en dicho país, la Fig. 5 muestra que en el 2010 las ventas tenían un excelente comportamiento y los siguientes tres años, la disminución que se obtuvo no era significativa, pero con una tendencia a la baja con una fuerte caída del 60\% en ventas en el año 2014 con respecto al 2013. Este comportamiento de disminución del consumo en el mercado en interno fue uno de las razones por las que Ecuador decidió utilizar la medida de salvaguarda. En el mismo gráfico, vemos como en 2015 , después de adoptada la medida hay una recuperación en la venta del mercado doméstico del 118\% con respecto al 2014.
Por su parte, las exportaciones de producto manufacturado en México hacia Ecuador muestran una disminución del $42 \%$ de caída en ventas comparando el 2015 respecto al año 2010. En la Fig. 6, observamos cómo los niveles de exportación se mantienen estables entre 2010 y 2013, y a partir del 2014 vemos una caída de un 29 \% respecto al año anterior, debido a que las condiciones del mercado interno en Ecuador ya empezaban a ser adversas para la importación de productos. En 2015, con la imposición de la sobretasa arancelaria, las exportaciones vuelven a caer un $23 \%$ adicional, llevando los niveles de exportación de producto al más bajo en el último lustro.

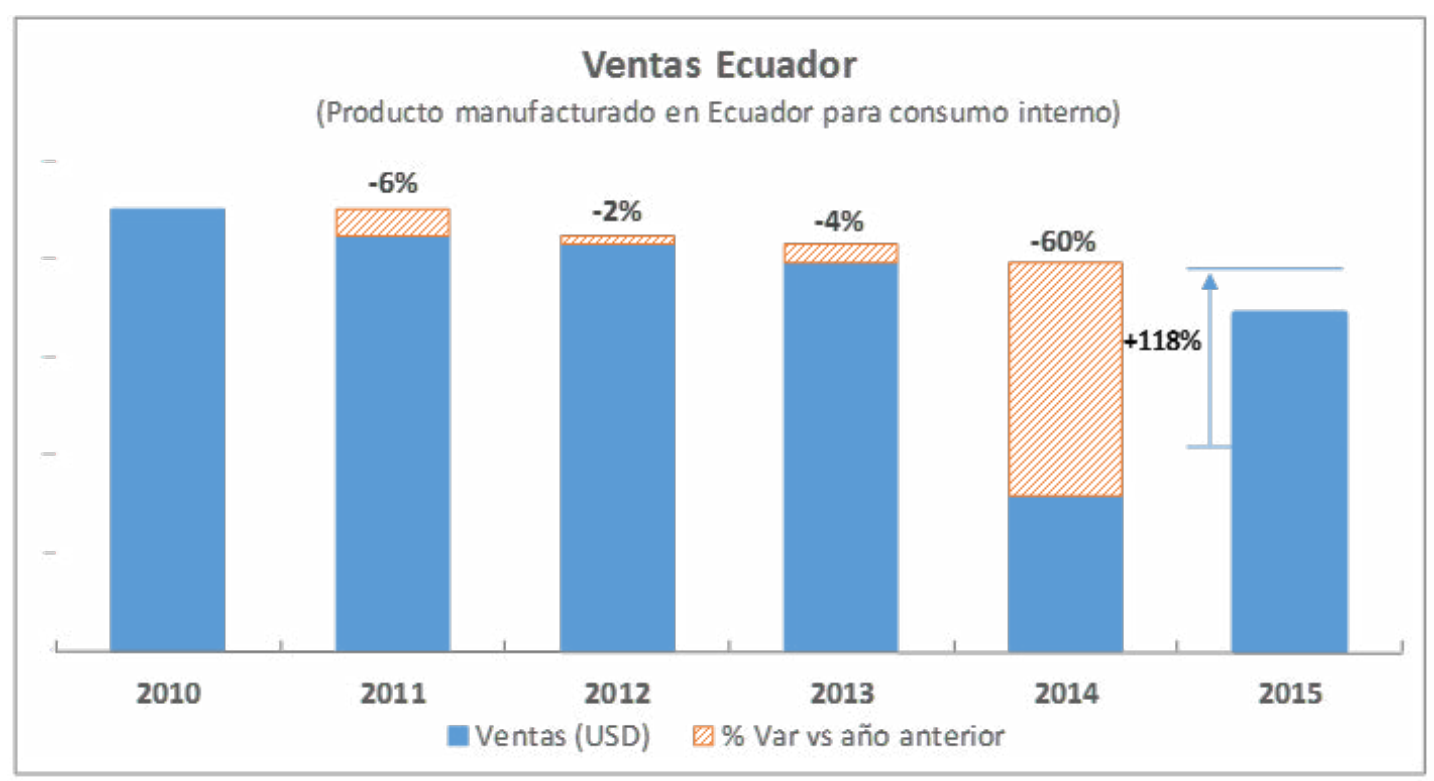

Figura 5. Ventas en Ecuador de producto doméstico

Figure 5. Sales in Ecuador of domestic product Fuente: elaboración propia. 


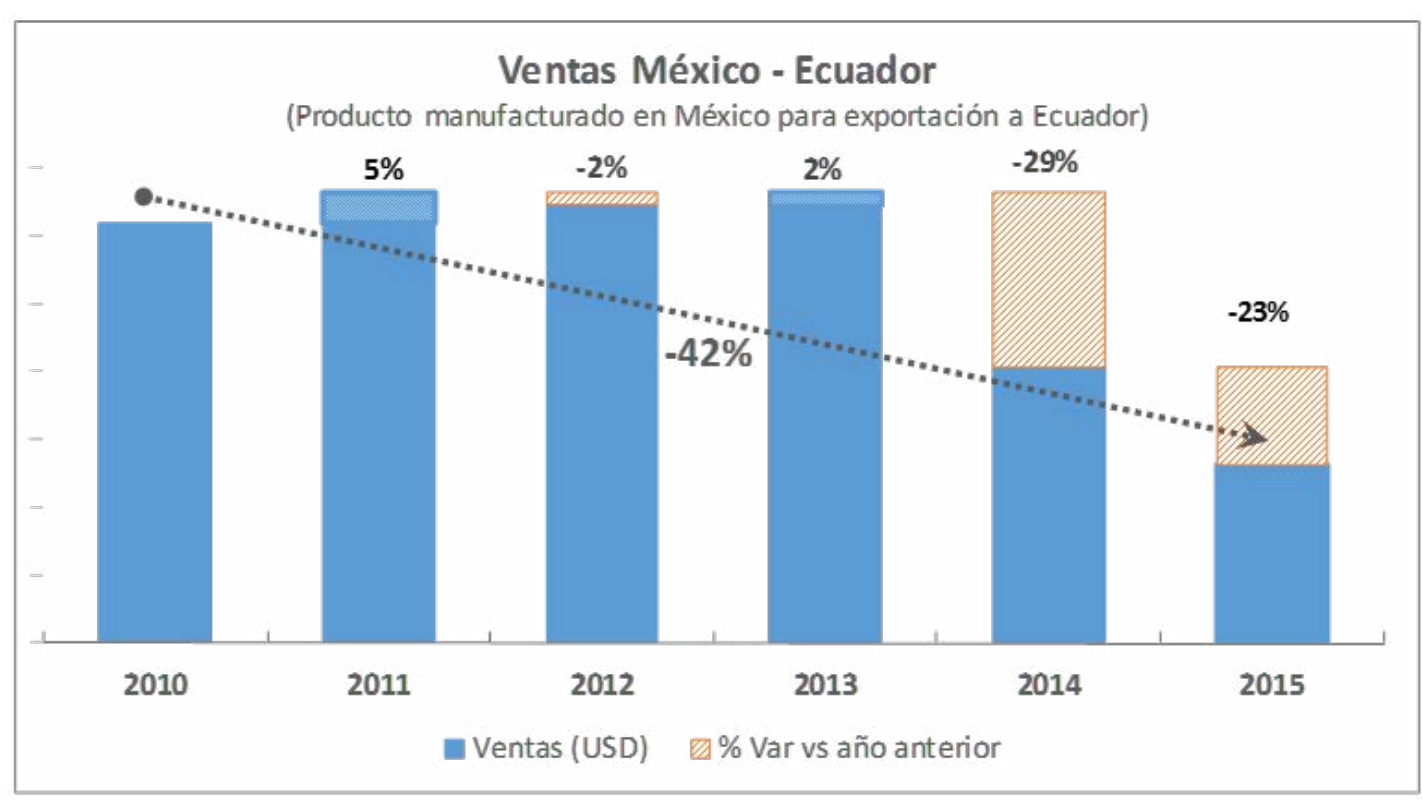

Figura 6. Exportaciones de México a Ecuador

Figura 6. Exports from Mexico to Ecuador Fuente: elaboración propia.

En la Fig. 7, observamos el comparativo del comportamiento de las ventas entre el producto manufacturado en Ecuador para consumo interno y el producto manufacturado en México para exportación hacia Ecuador. En ambos casos, vemos cómo se mantienen las ventas relativamente estables entre los años 2010 y 2013. En 2014, ambos productores (nacional y extranjero) muestran una importante caída debido a las condiciones del mercado; sin embargo, en 2015, el efecto de la medida arancelaria causa una caída aún mayor para el proveedor mexicano, pero una recuperación para los productores locales.

El análisis de la información permite registrar que las medidas de salvaguardas incrementaron el costo de exportación de un año a otro en un $80 \%$. Además, como lo vemos en la Fig. 8, este aumento representa un impacto del $137 \%$ con respecto al 2010, en el costo de importación de un producto proveniente de México. Para el consumidor, este incremento en costo de importación se ve reflejado en un aumento en precio al momento de adquirir el producto. Los productores locales se beneficiaron, además de la disminución del nivel de importaciones, con un incremento en precio para el producto nacional, lo que representa un aumento en los ingresos por venta, para los productores locales en volumen y en utilidad por producto.

Por último, la Fig. 9 evidencia la relación que existe entre en el costo del arancel y las ventas para la empresa; en este último gráfico, observamos que cuando se mantiene estable el costo del arancel, las ventas mantienen su nivel también estable, sin embargo, con el aumento significativo del $137 \%$ en el costo de arancel con respecto al 2010, notamos la afectación para el exportador mexicano con una caída del $42 \%$ en sus ventas. 


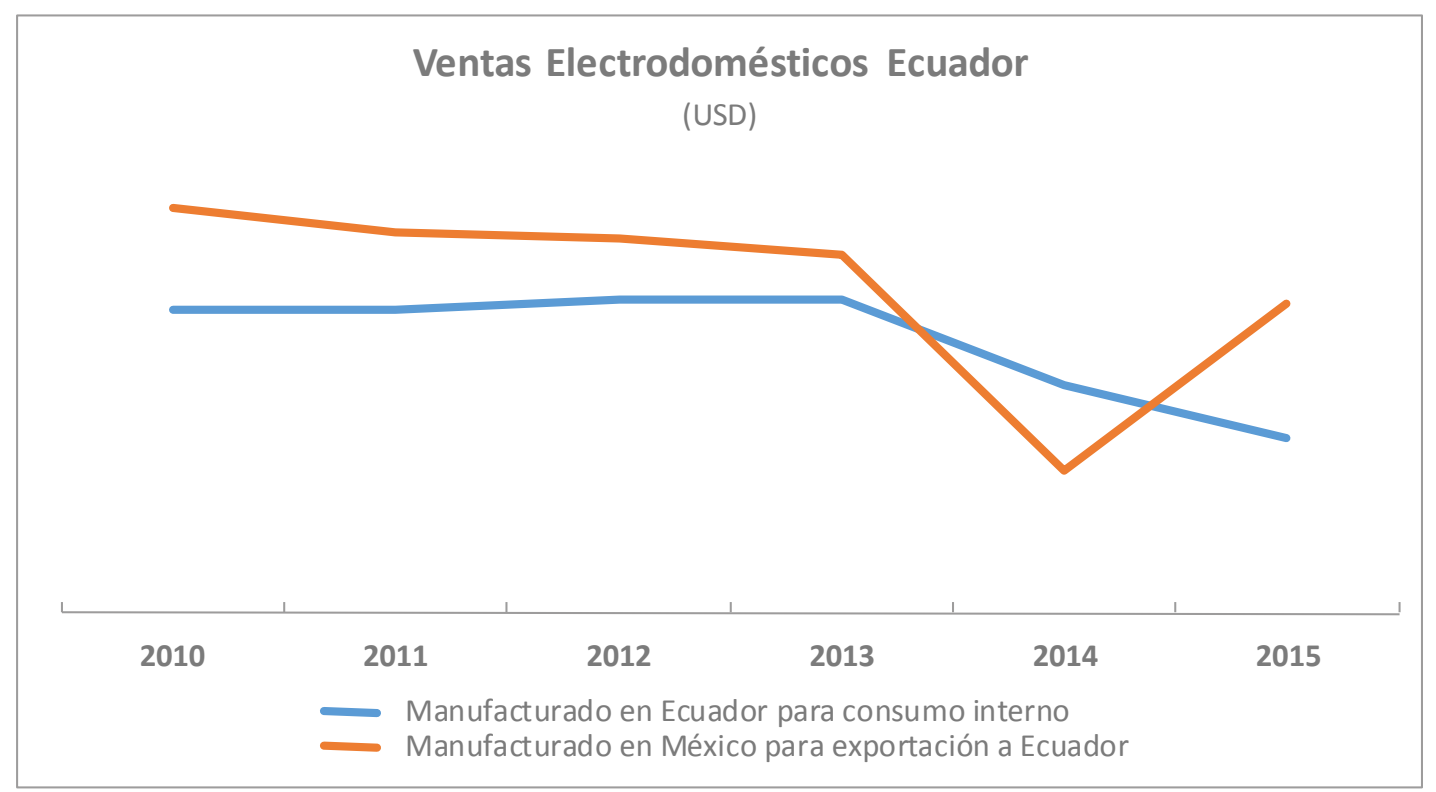

Figura 7. Ventas Ecuador (producto nacional vs importado)

Figure 7. Sales Ecuador (national vs. imported product)

Fuente: Elaboración propia.

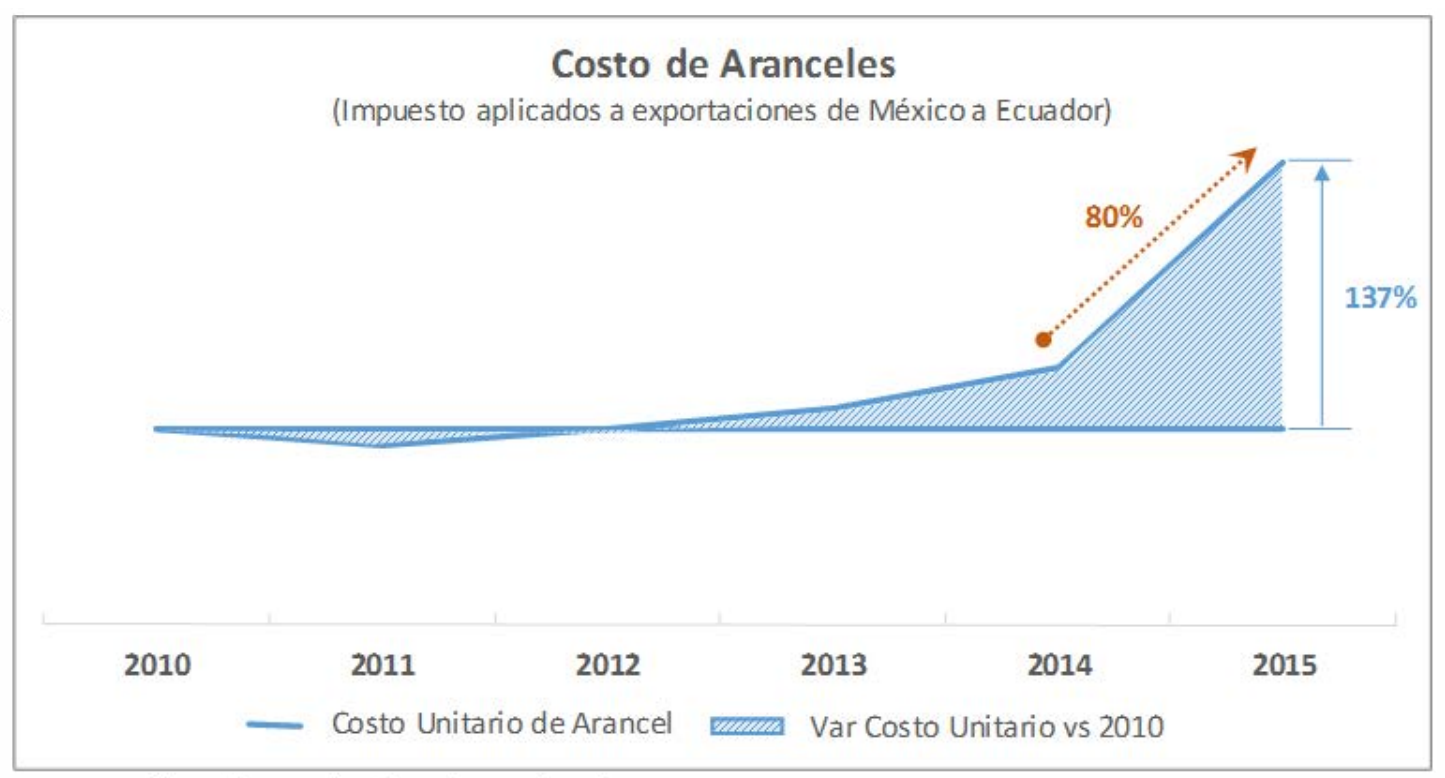

FUENTE: Elaboración Propio bosada en datos recolectodos

Figura 8. Costo de Aranceles

Figura 8. Cost of Fees

Fuente: Elaboración propia. 


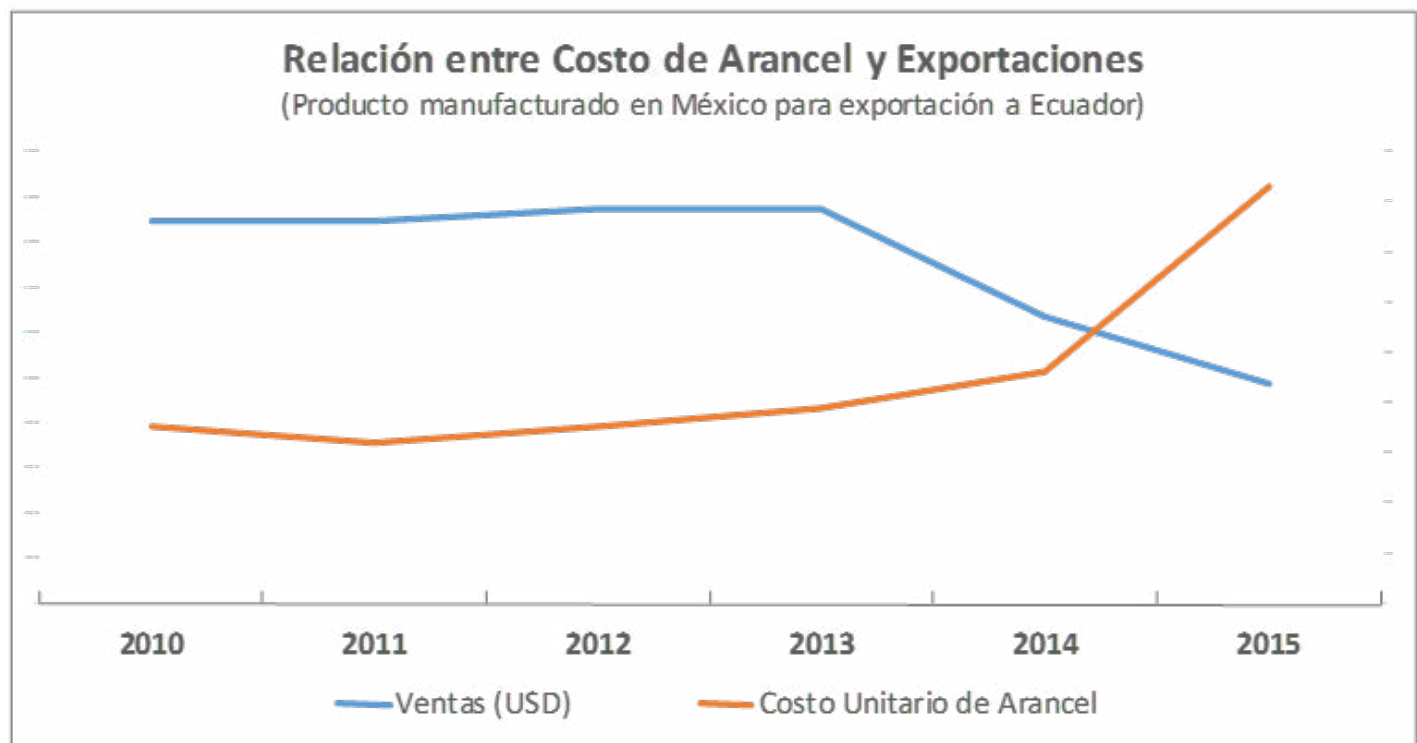

Figura 9. Relación entre Costo de Arancel y Exportaciones

Figure 9. Relationship between Tariff Cost and Exports

Fuente: Elaboración propia.

\section{CONCLUSIONES}

El comercio ha cambiado su estructura a lo largo del tiempo. México no ha sido excepción de esta evolución hacia la apertura comercial, sin embargo, a pesar de tener una extensa red de tratados comerciales, en el caso específico de las relaciones comerciales que México sostiene con Ecuador, no existe un tratado de libre comercio, es un acuerdo de alcance parcial el que rige el intercambio comercial entre los países.

Las medidas arancelarias, como las salvaguardas que buscan frenar las importaciones de productos a un país para proteger el sector interno, puede llevar al cierre de la relación comercial entre los países como lo mencionan O'Sullivan et al (2003), al afirmar que tienden a limitar el comercio pues los exportadores ven una disminución es sus ventas debido al alto costo de impuestos. Para el caso específico de la empresa en estudio, significó una importante disminución del 23\% en sus ventas de un año contra otro para el caso de México, sólo en el último año.

Adicional, el impacto por la imposición de salvaguardas del $80 \%$ de incremento en costo de arancel en el 2015 con respecto al año anterior en México, que es más dramático al venir de una tasa arancelaria de 0 y verla incrementada hasta el $75 \%$ de acuerdo al producto, orilló a la empresa a incrementar el precio de venta del producto exportado al consumidor en Ecuador.

Para el producto manufacturado en Ecuador, observamos una recuperación en las ventas en el mismo periodo, impulsadas por la medida de protección al sector interno que tuvo como efecto un aumento en la producción y ventas para los nacionales como lo mencionan González et al (2014).

La compañía exportadora, en respuesta a la imposición arancelaria, tiene como estrategia impulsar el crecimiento en mercados alternos para recuperar las ventas perdidas en Ecuador. 
Dado que la medida de salvaguardas es de carácter temporal, y que Ecuador ha anunciado el fin de la sobretasa, se espera recuperar en 2016 de forma gradual el nivel de ventas que se tenía en 2014 antes la imposición de la medida, sin embargo, no se tiene proyectada una recuperación en los niveles de exportaciones que la empresa tenía en 2010.

Otro aspecto a resaltar, es que además de la empresa que se ve afectada en la disminución de exportaciones hacia Ecuador otro gran afectado es el consumidor final. La empresa puede buscar alternativas para recuperarse de las pérdidas, que implican una medida proteccionista en un mundo cada más orientado a la apertura comercial, sin embargo, estas medidas representan para el consumidor perder la oportunidad de tener más opciones de consumo, y que además se ve obligado a incluso dejar de consumir estos productos 0 pagarlos a un precio muy por encima del valor al que se les veía ofreciendo. Incluso al eliminarse la competencia, los estándares de la industria se pueden ver comprometidos en calidad y precio.

Es por ello que al aplicar este tipo de medidas debe realizarse un análisis del impacto en los diferentes sectores de la sociedad, ya que, si bien el objetivo es asegurar y equilibrar la economía del país, el impacto en las industrias, el desempleo y la reducción de solvencia económica de la sociedad, es algo digno de medir para que la aplicación de una salvaguarda no genera un mayor impacto negativo que positivo.

\section{REFERENCIAS}

Ballesteros, A. J. (1998). Comercio Exterior: teoría y práctica ( $1^{\circ}$ edición). España: Universidad de Murcia. Servicio de Publicaciones.
Benavides, G. M. (2013). Impacto de la aplicación de salvaguardias arancelarias en el flujo Comercial Ecuador-ColombiaAnálisis del periodo 2009-2011 (Bachelor's thesis, QUITO/PUCE/2013).

Bengochea, A.; Camarero, M.; Cantavella M. y Martínez, I. (2002). Economía Internacional: Cuestiones y ejercicios resueltos. España. Pearson Prentice Hall.

González, M. J.; Pérez, A.; Castejón, R.; Méndez, E.; Martínez, J. L.; Gómez, J. L. y Mochón, A. (2009). Introducción a la Economía. Pearson Prentice Hall. España.

González, I.; Martínez, A. I.; Otero, M. C. y González, E. (2014). Gestión del comercio exterior de la empresa, manual teórico y práctico (3a. Edición). España. ESIC Editorial.

Krugman, P. R.; Obstfeld, M. y Melitz, M. (2012). Economía Internacional: teoría y práctica. (9a. Edición). España. Pearson Prentice Hall.

Mendoza, A. P. (2006). Análisis del efecto económico de la aplicación de una medida de salvaguarda: el caso de la industria del triplay. Economía mexicana Nueva Época, 15(1).

Mochón, F. (2008). Economía Principios y Aplicaciones (4a. Edición). Argentina, Mc. Graw Hill.

Muñoz, D. E. (2017). Valoración del impacto que tienen las salvaguardias, enfocado al sector automotriz (cd Chevrolet) en Quito periodo 2015-2016 (Bachelor's thesis). 
O'Sullivan, A. y Sheffrin, S. (2003). Economía: Principios e instrumentos (3a. Edición). España. Pearson Prentice Hall.

Osorio, C. (1995). Diccionario de Comercio Internacional. México. Grupo Editorial Iberoamérica.

Samuelson, P. y Nordhaus, W. (2005). Economía (18va. Edición). México. McGraw Hill Interamericana.

Vera, M. (2015). Información y gestión operativa de la compraventa internacional. Relaciones comerciales exteriores. España: Ideaspropias.

Witker, J. y Hernández, L. (2008). Régimen jurídico del comercio exterior de México (3a. Edición). México. Instituto de Investigaciones Jurídicas de la UNAM.

Artículos recuperados de internet:

Bancomext. (2015). Definición Salvaguardas. Banco de Comercio Exterior (Bancomext). Recuperado de http://www.bancomext.com/soporte/glos ario

Ceballos, L. (2012). Qué es comercio exterior. Instituto Nacional de Comercio Exterior y Aduanas (INCEA). Recuperado de http://www.comercioyaduanas.com.mx/c omercioexterior/comercioexterioryaduana s/116-que-es-comercio-exterior

De la Mora, L. M. (2015). El comercio exterior como palanca del crecimiento económico y crecimiento de México. Comercio Exterior Bancomext. Recuperado de http://revistacomercioexterior.com/articul o.php?id=81\&t=el-comercio-exteriornbspcomo-palanca-del-crecimientonbspeconomico-y-desarrollo-de-mexico

Organización Mundial del Comercio. (2005). Definición de Arancel. Organización Mundial del Comercio (OMC). Recuperado de

https://www.wto.org/spanish/tratop_s/tar iffs_s/tariffs_s.htm

ProMéxico. (2010). Industria de electrodomésticos. Secretaría de Economía, México. Recuperado de http://mim.promexico.gob.mx/work/sites/ $\mathrm{mim} /$ resources/LocalContent/319/2/Indus tria_de_electrodomesticos.pdf

ProMéxico. (2014). Industria electrodomésticos. Secretaría de Economía, México. Recuperado de http://mim.promexico.gob.mx/work/sites/ $\mathrm{mim} /$ resources/LocalContent/322/2/1501 13_Electrodomesticos_ES.pdf

ProMéxico. (2015). Comercio Exterior / Países con tratados y acuerdos firmados con México. Secretaría de Economía, México. Recuperado de http://www.gob.mx/se/acciones-yprogramas/comercio-exterior-paises-contratados-y-acuerdos-firmados-con-mexico

ProMéxico. (2015). Proméxico y Proecuador Organizan Seminario «Hablemos de Negocios con Ecuador: Oportunidades de Internacionalización». Secretaría de Economía, México. Recuperado de https://www.promexico.gob.mx/documen tos/boletines-prensa/Boletin-Prensa-0615.pdf 
ProMéxico. (2015). Sector de electrodomésticos en México. Secretaría de Economía, México. Recuperado de http://mim.promexico.gob.mx/wb/mim/el ect_perfil_del_sector_1 